\title{
The Gleaner
}

Vol 20 (1995)

\section{O EPANI $\Sigma$ TH $\Sigma$}

EKAOEH TOY "OMIAOY MEAETHE TOY EAAHNIKOY АIAФQTIEMOY,

$\operatorname{ETO\Sigma } \Lambda B^{\prime}-\Lambda \Gamma^{\prime}$

T O M O 20

AOHNA

1995

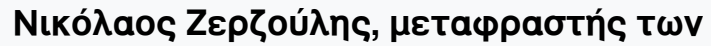

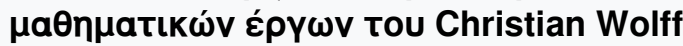

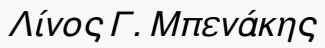

doi: $10.12681 / \mathrm{er} .238$

To cite this article:

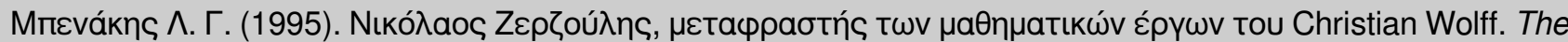
Gleaner, 20, 47-57. https://doi.org/10.12681/er.238 


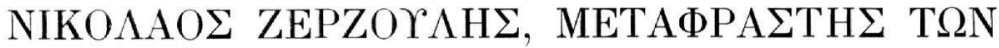

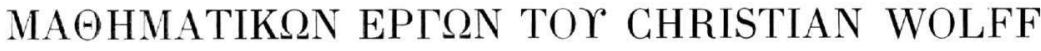

\begin{abstract}
O NIKOAAOE ZEPZOTAH

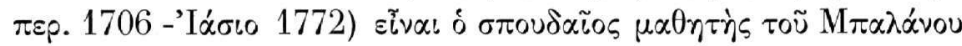

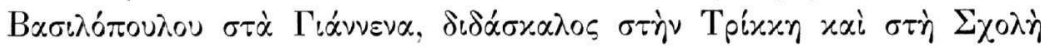

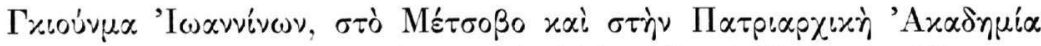

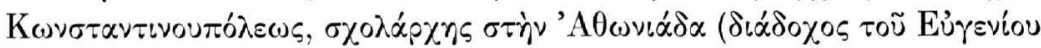

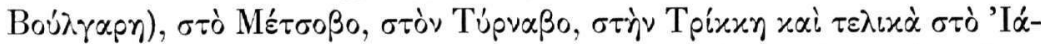

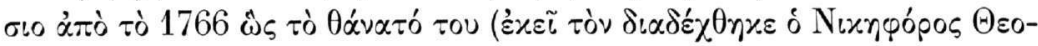

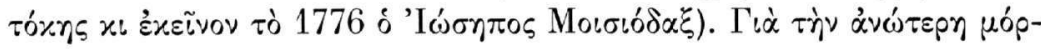

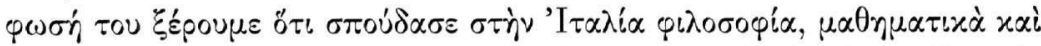

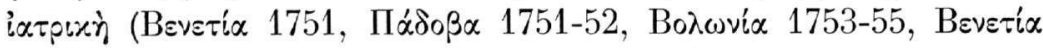

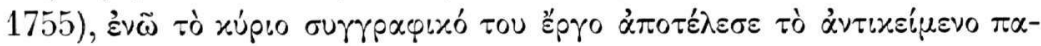

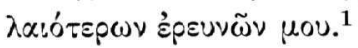

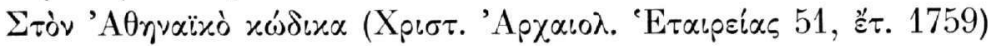

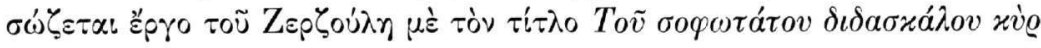

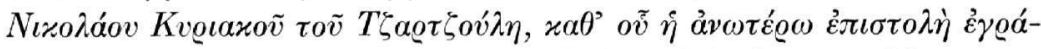

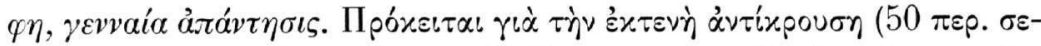

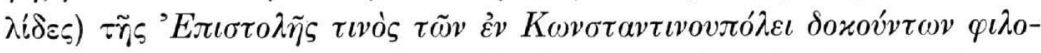

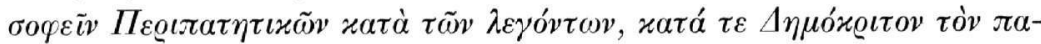

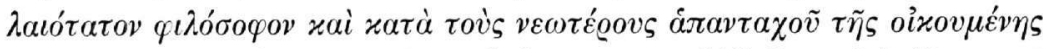

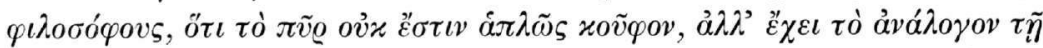

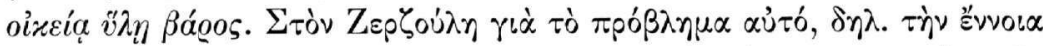

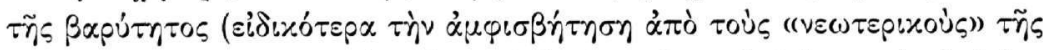

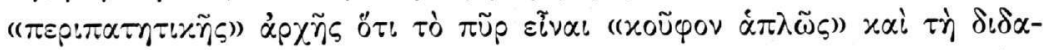

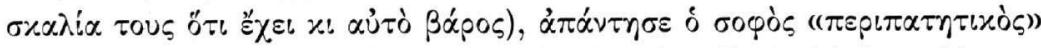

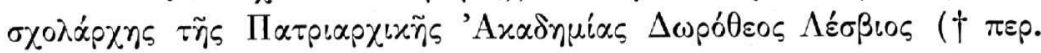

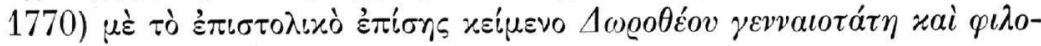

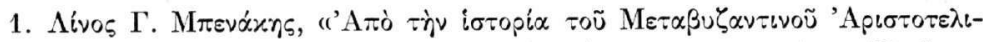

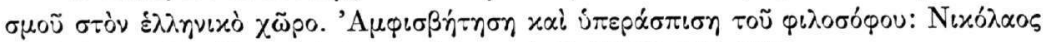

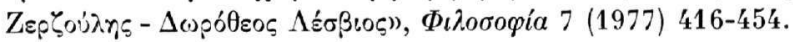




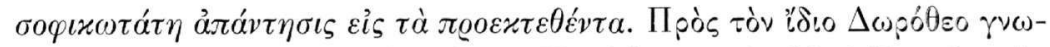

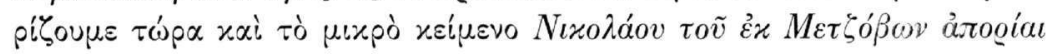

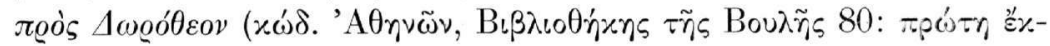

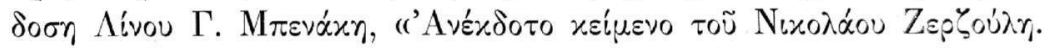

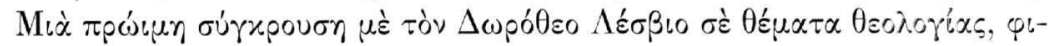

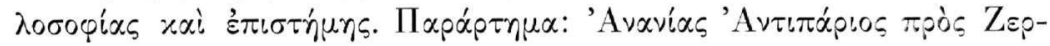

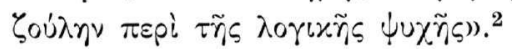

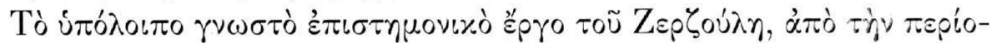

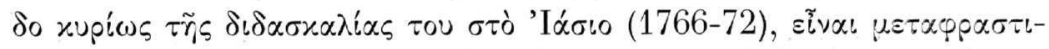

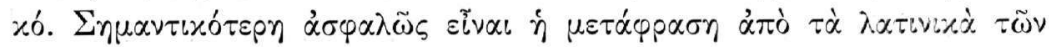

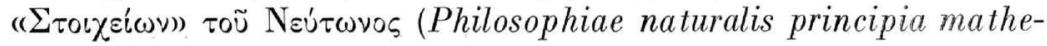

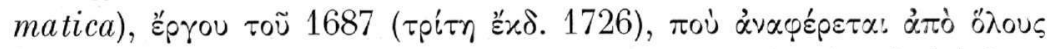

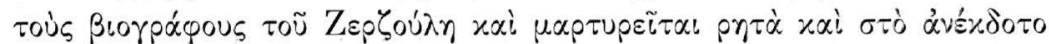

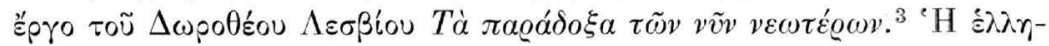

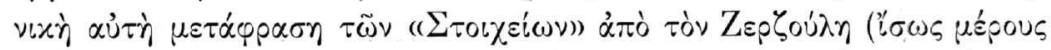

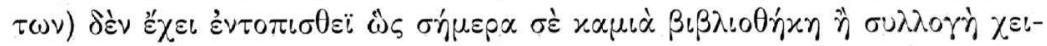

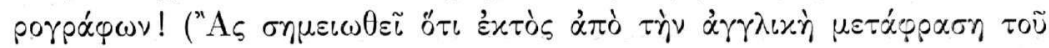

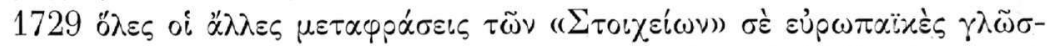

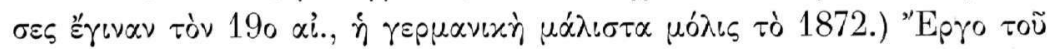

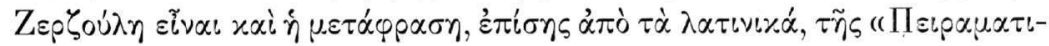

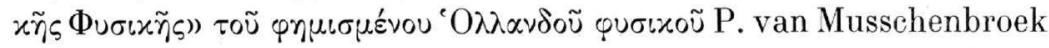

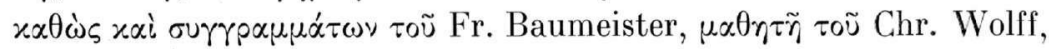

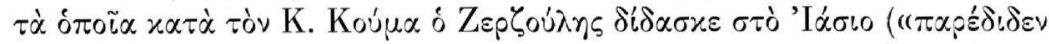

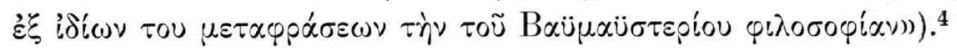

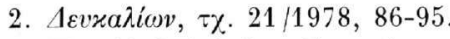

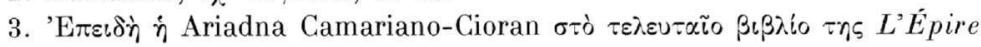

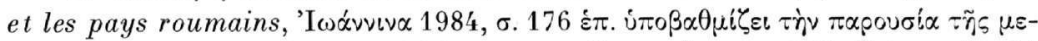

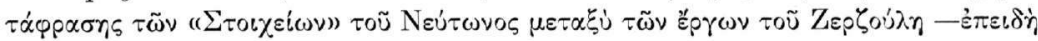

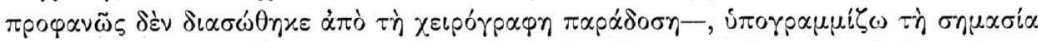

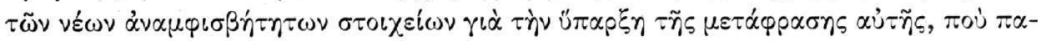

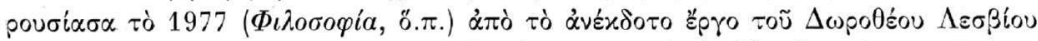

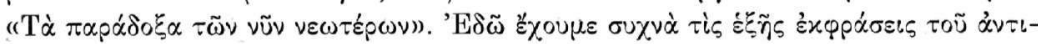

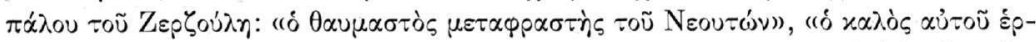

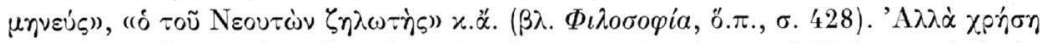

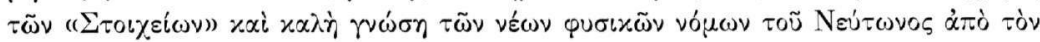

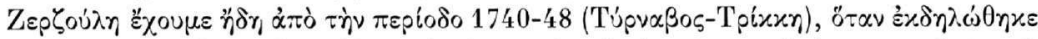

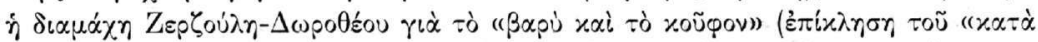

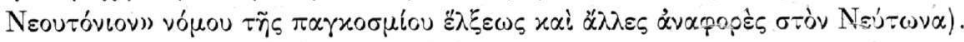

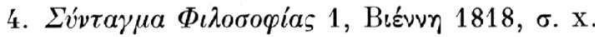




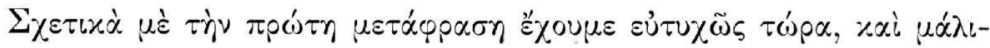

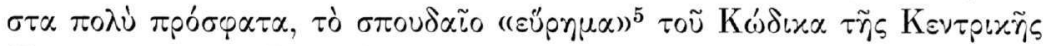

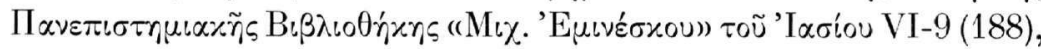

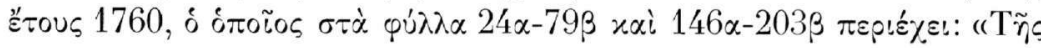

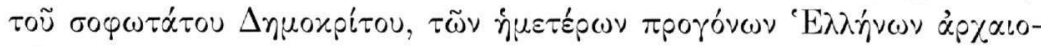

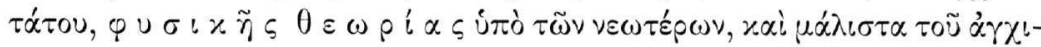

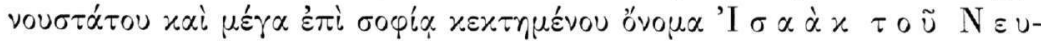

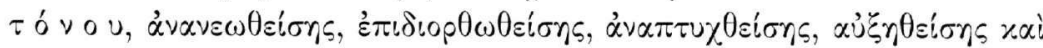

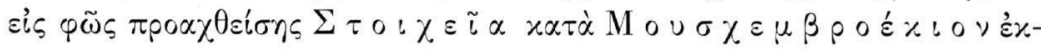

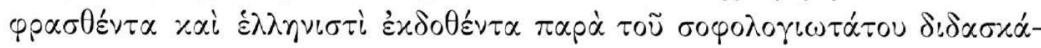

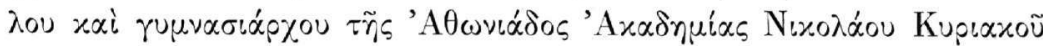

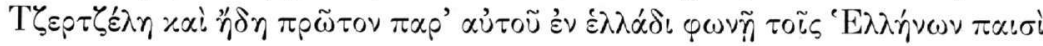

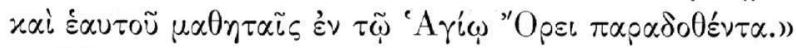

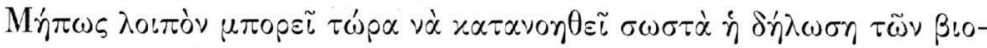

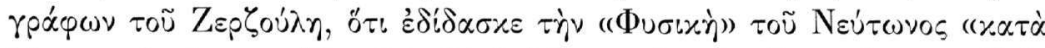

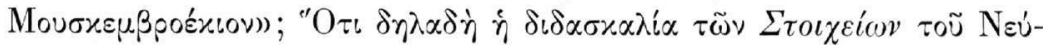

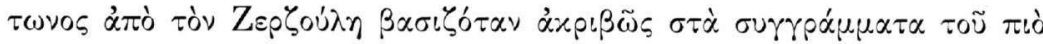

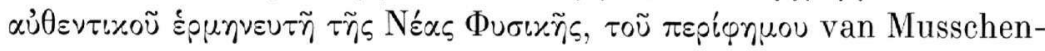

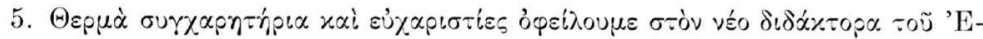

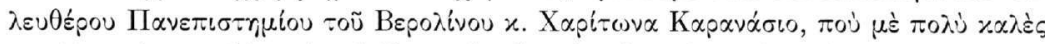

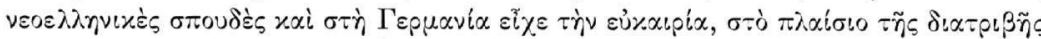

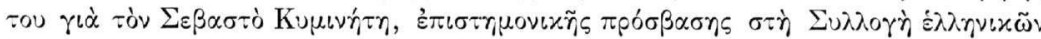

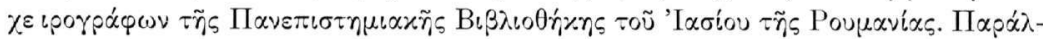

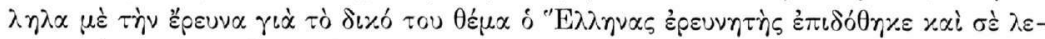

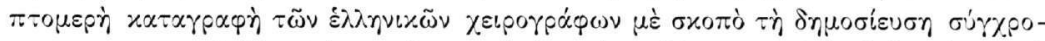

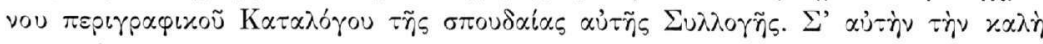

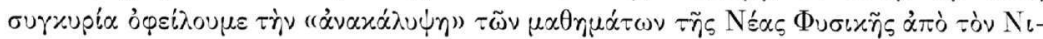

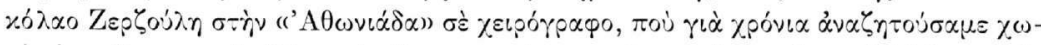

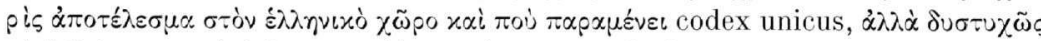

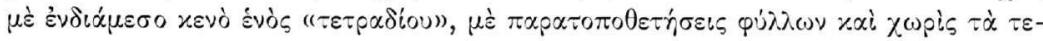

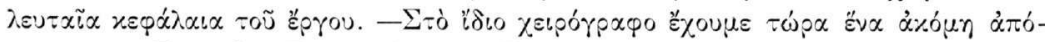

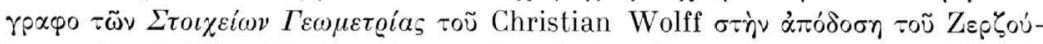

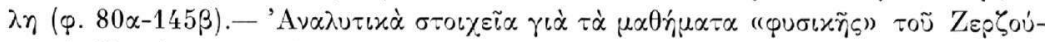

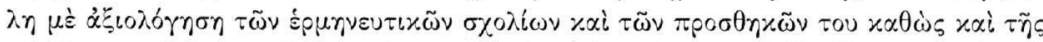

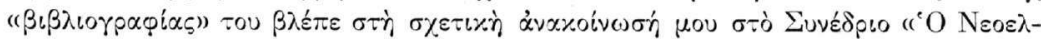

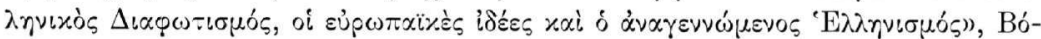

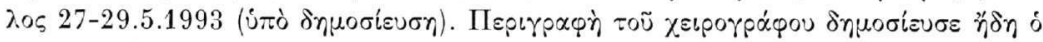

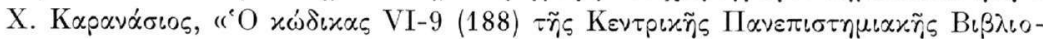

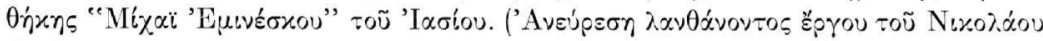

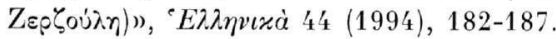




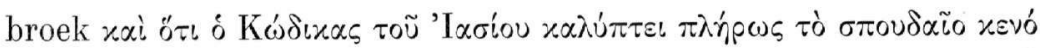

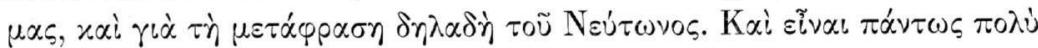

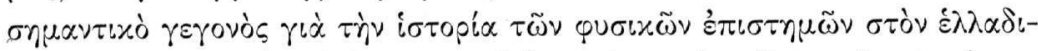

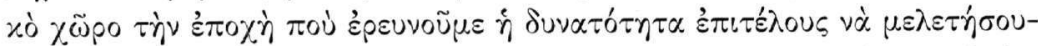

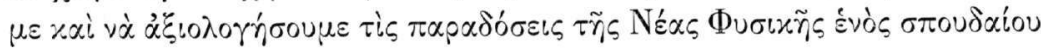

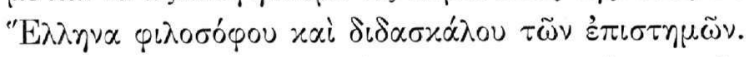

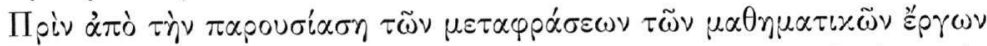

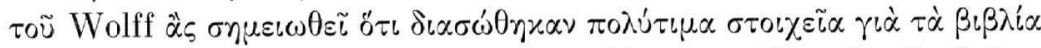

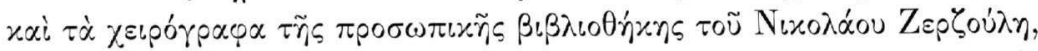

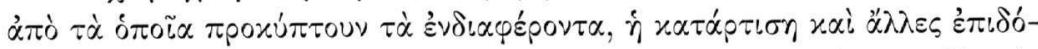

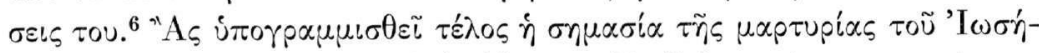

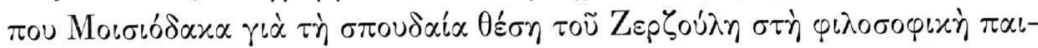

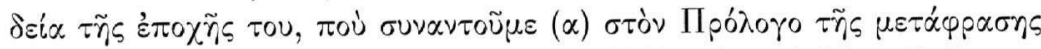

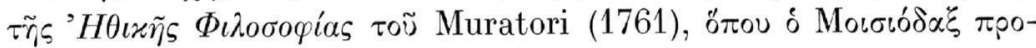

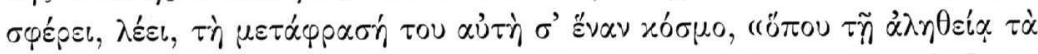

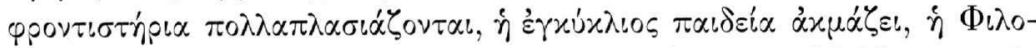

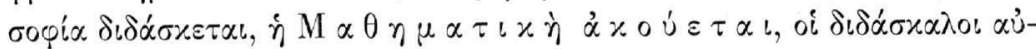

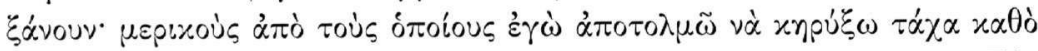

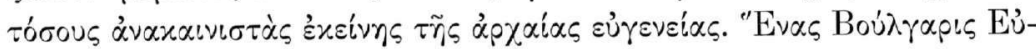

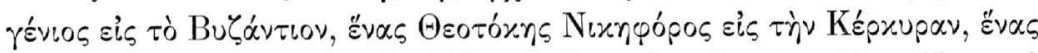

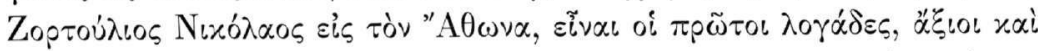

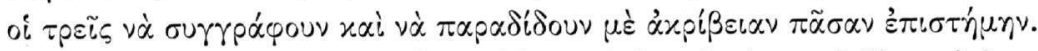

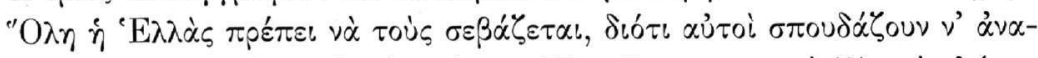

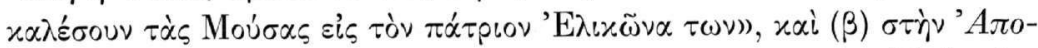

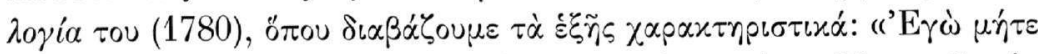

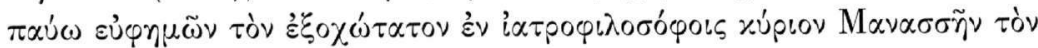

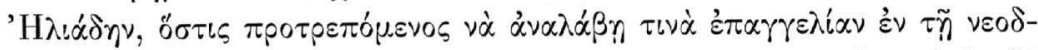

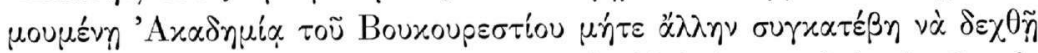

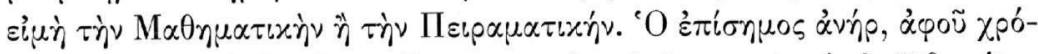

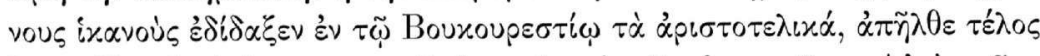

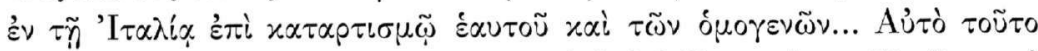

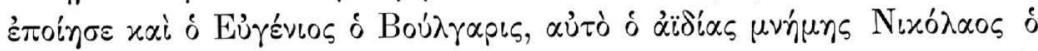

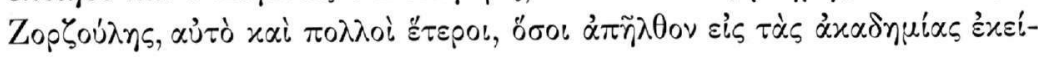

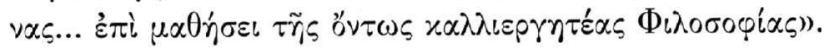

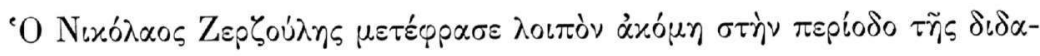

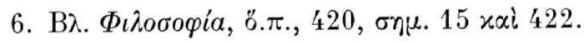




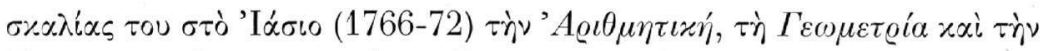

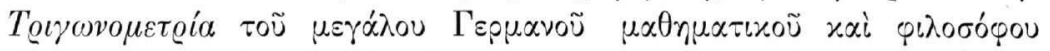

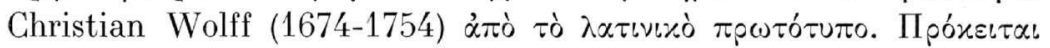

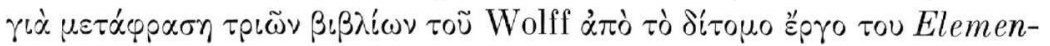

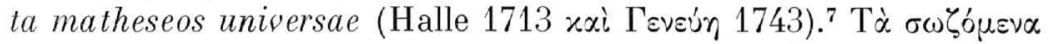

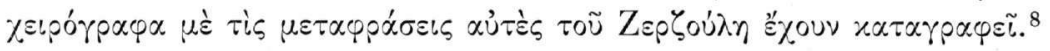

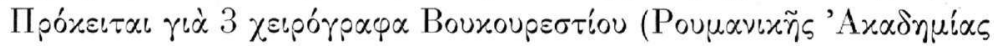

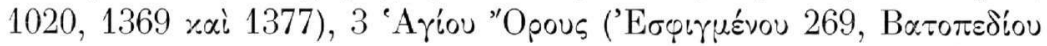

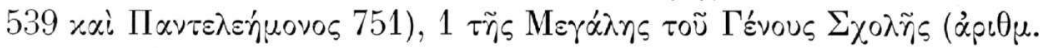

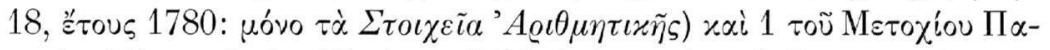

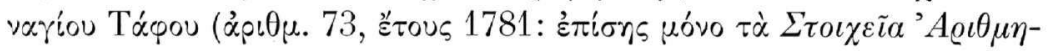

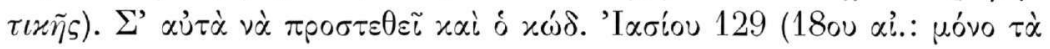

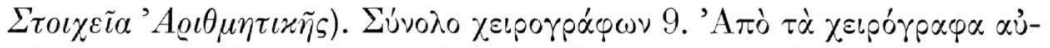

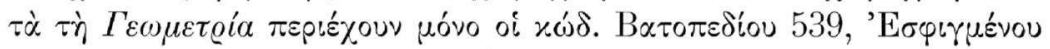

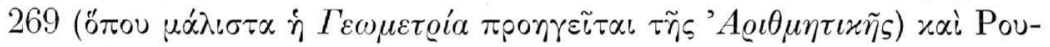

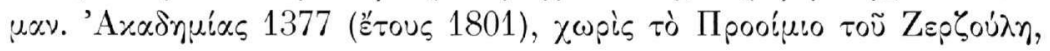

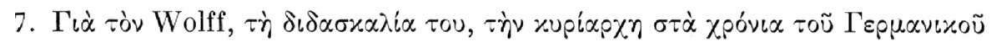

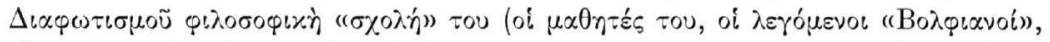

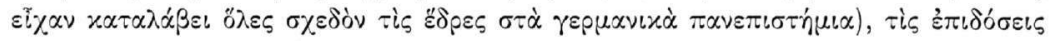

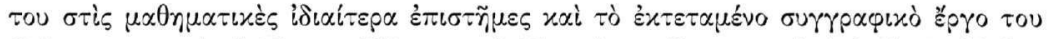

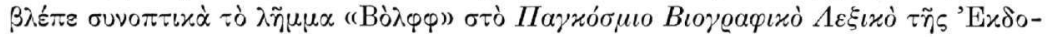

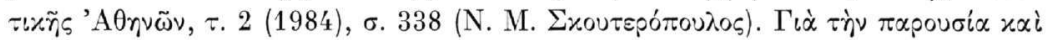

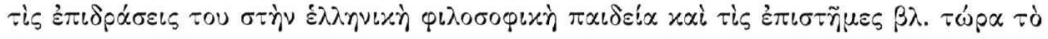

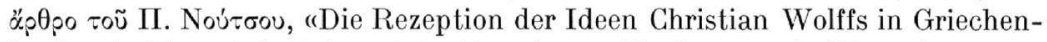

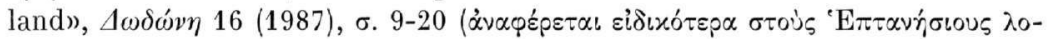

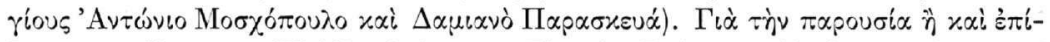

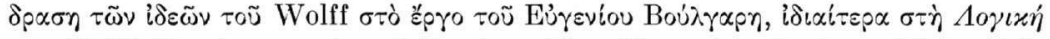

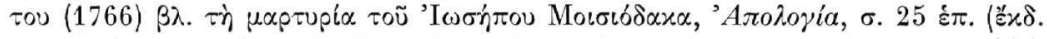

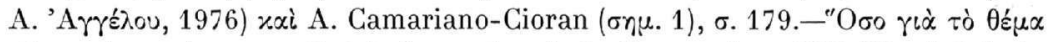

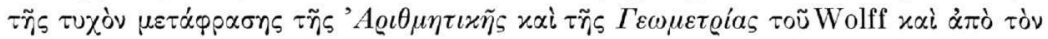

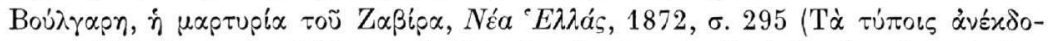

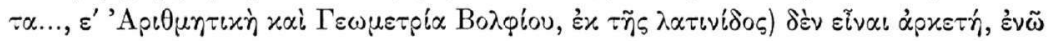

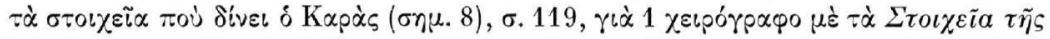

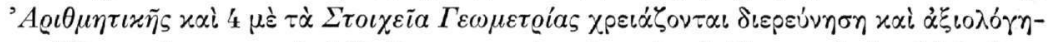

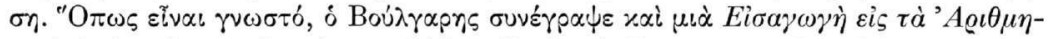

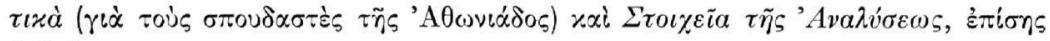

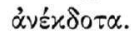

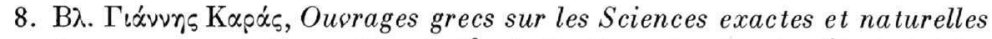

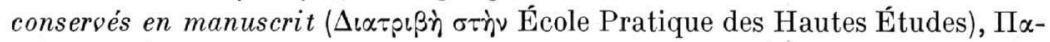

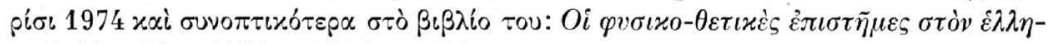
vเхò 180 aióva, 'A 


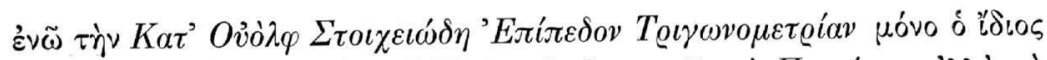

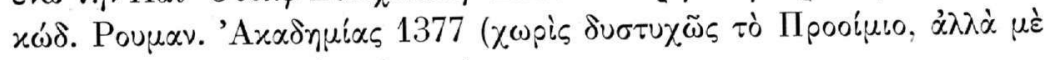
$\left.\pi 0 \lambda \lambda \dot{\alpha} \pi \alpha \rho \alpha \delta \varepsilon \iota \gamma \mu \alpha \tau \iota x \dot{\alpha} \alpha \chi \chi_{\eta}^{\prime} \mu \alpha \tau \alpha\right)$.

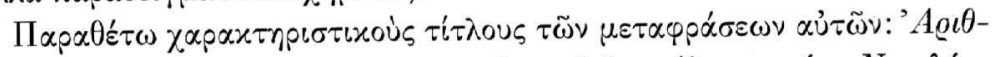

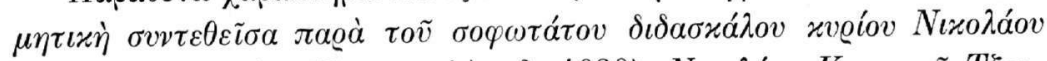

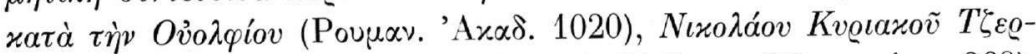

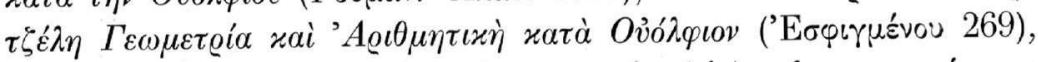

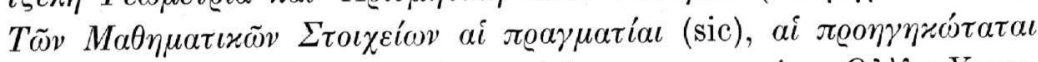

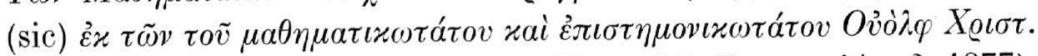

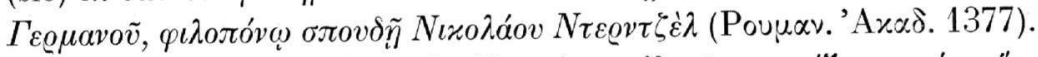

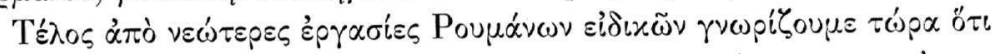

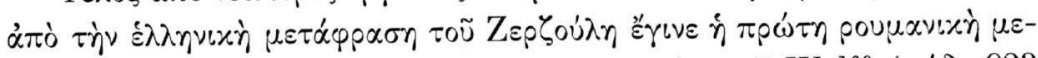

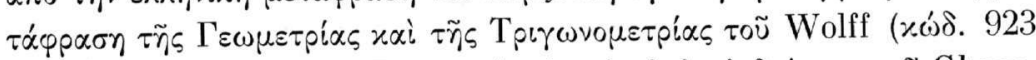

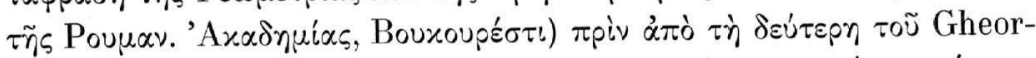

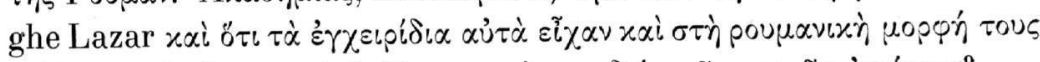

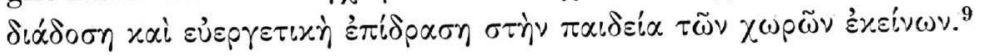

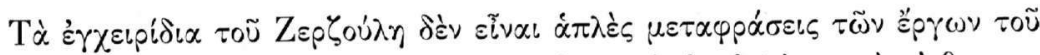

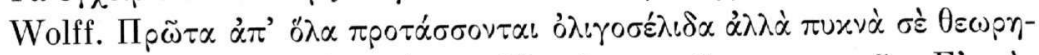

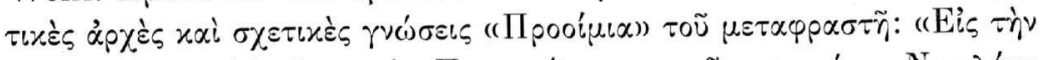

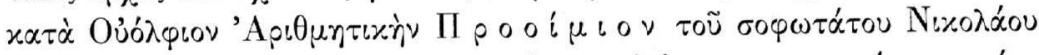

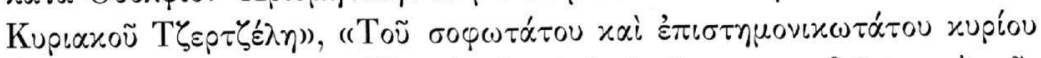

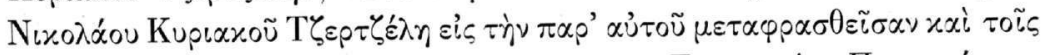

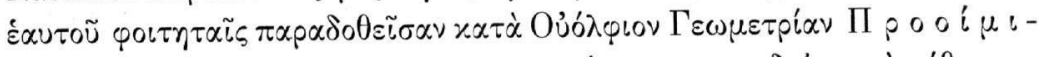

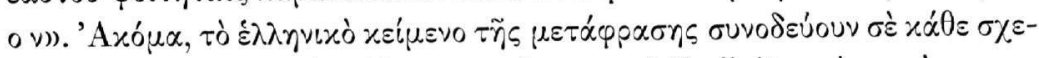

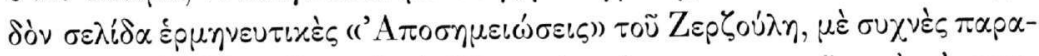

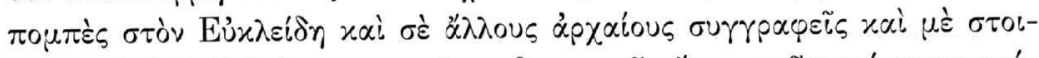

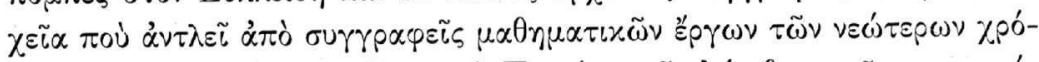

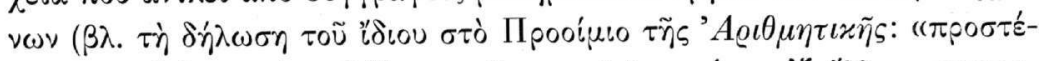

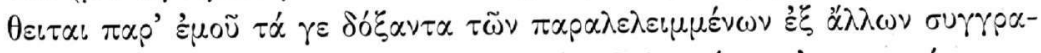

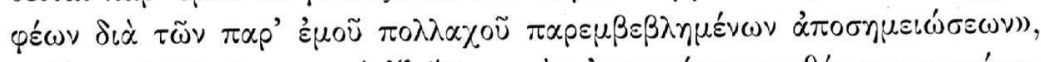

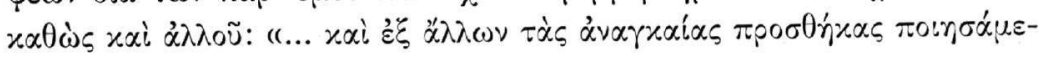
vos)).

9. B入. Florica Cîmpan, “Un manuscris moldovenesc cuprinzînd o traducere a geometrei si trigonometriei lui Wolff, anterioară celei făcute de Gh. La-

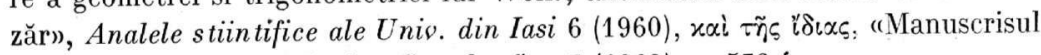

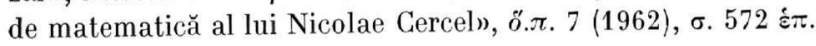




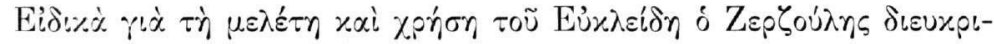

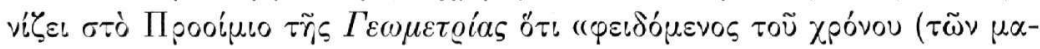

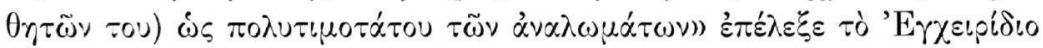

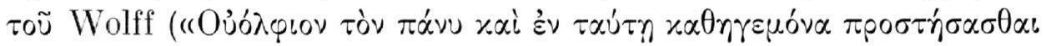

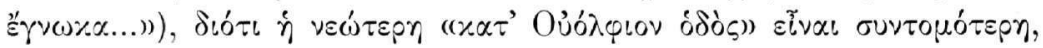

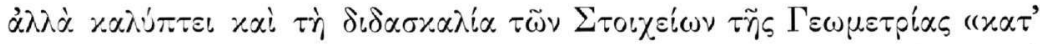

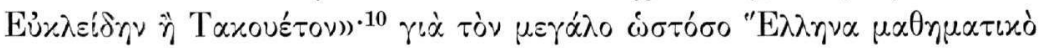

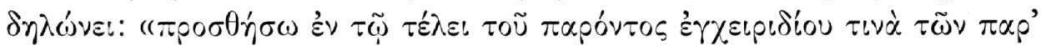

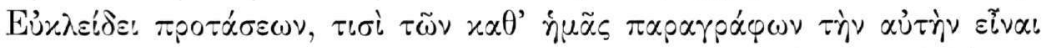

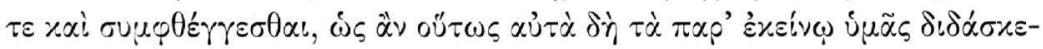

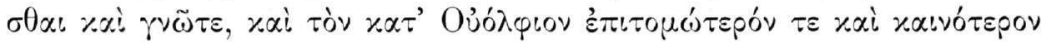

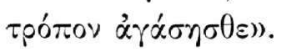

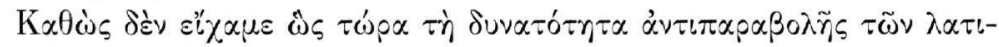

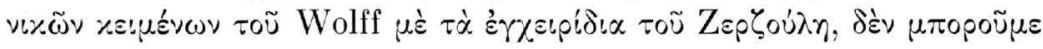

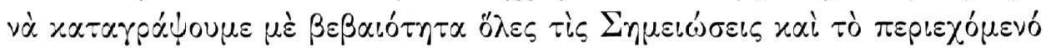

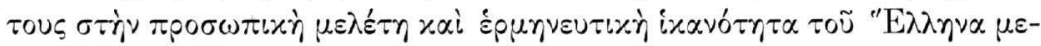

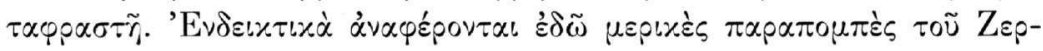

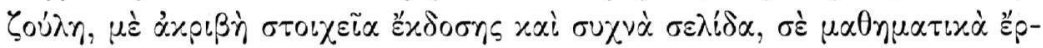

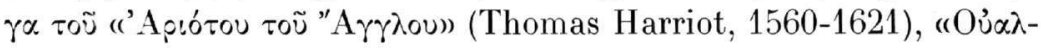

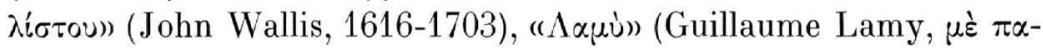

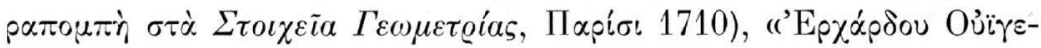

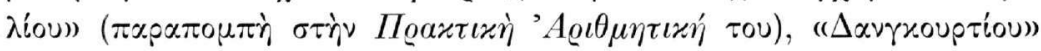

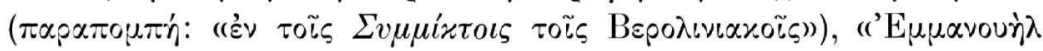

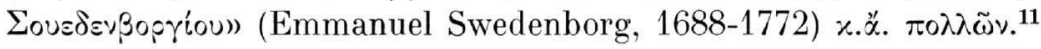

10. T’̀ Elementa Geometriae -oũ Andreas Tacquet (Cantabrigiae 1710)

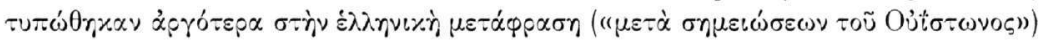

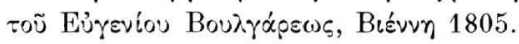

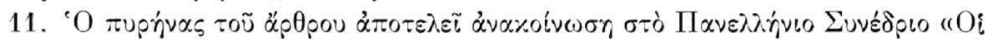

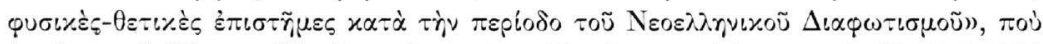

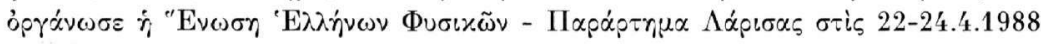

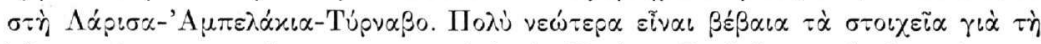

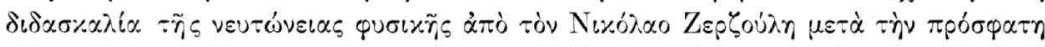

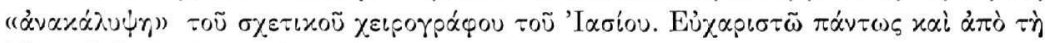

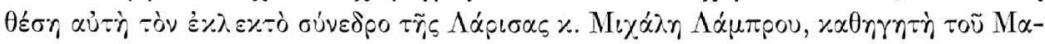

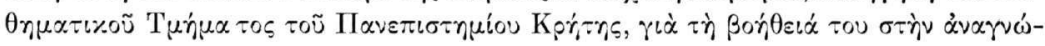

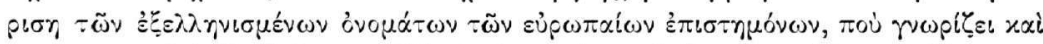

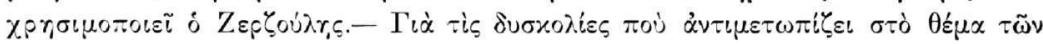

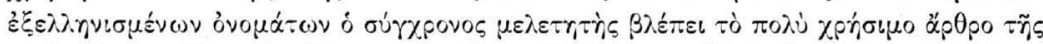

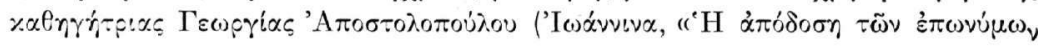




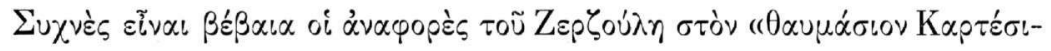

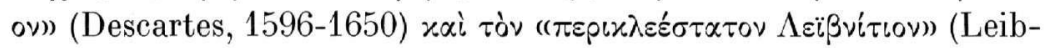

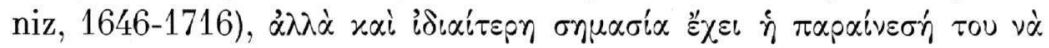

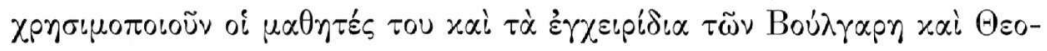

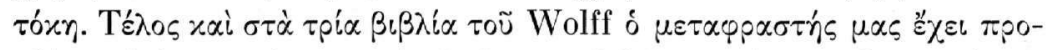

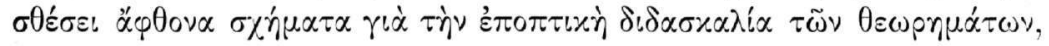

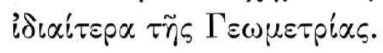

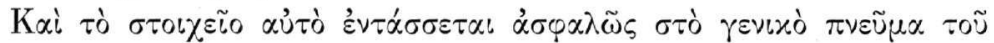

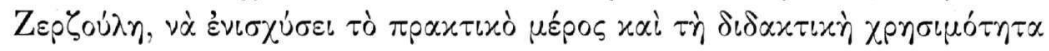

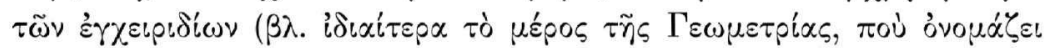

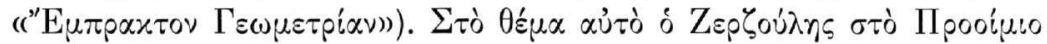

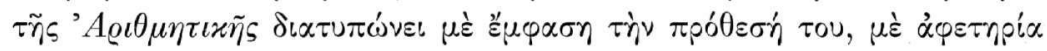

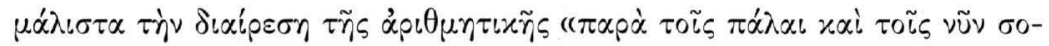

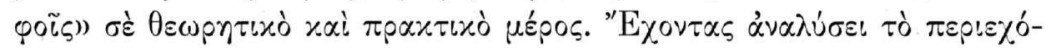

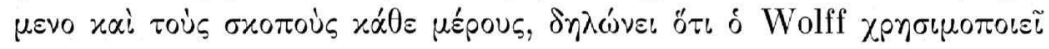

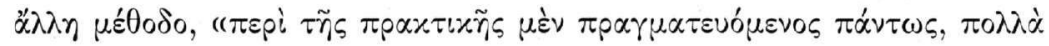

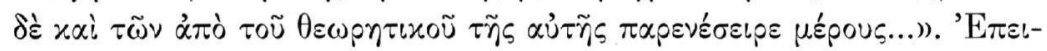

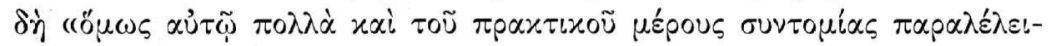

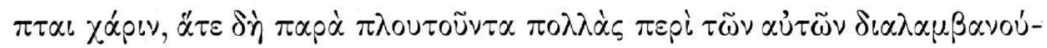

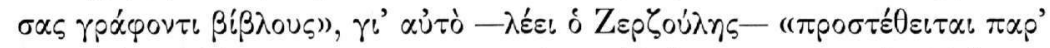

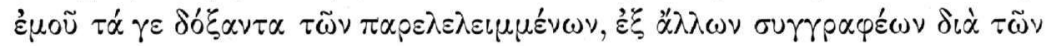

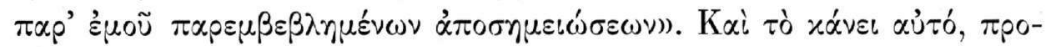

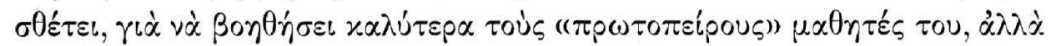

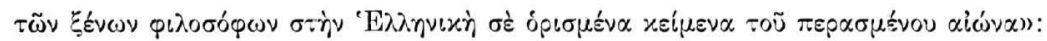

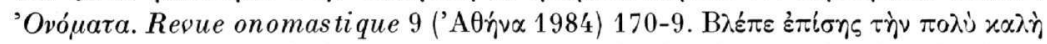

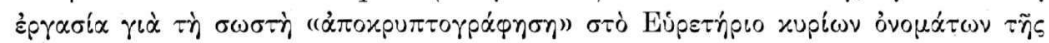

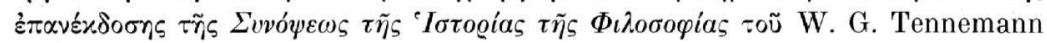

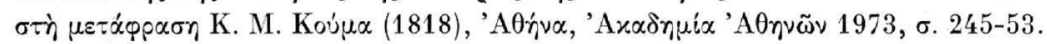

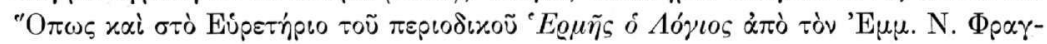

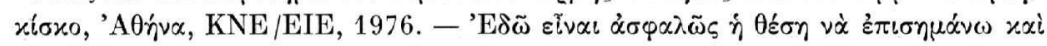

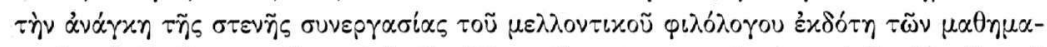

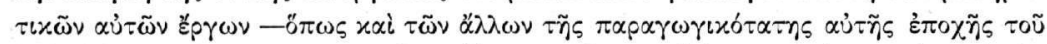

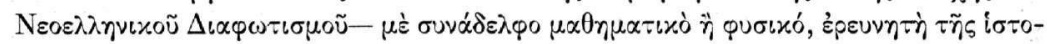

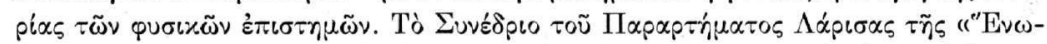

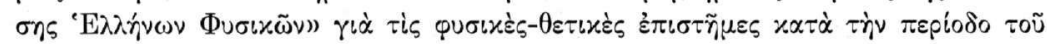

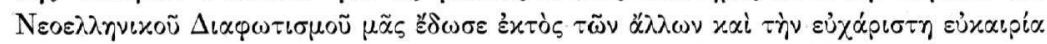

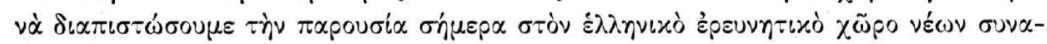

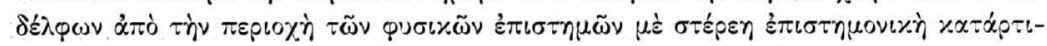

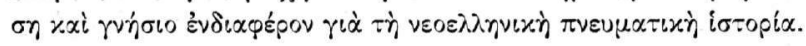




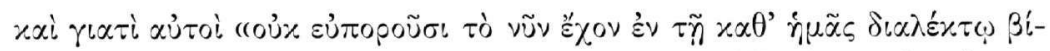

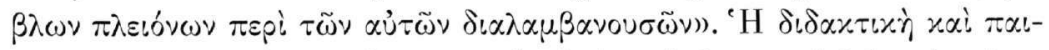

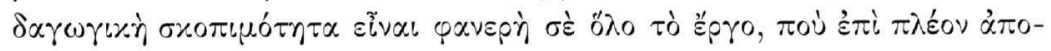

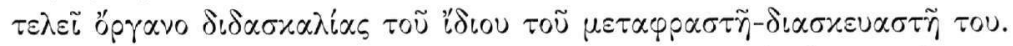

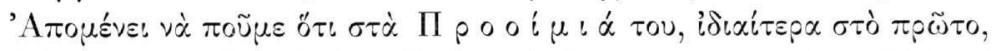

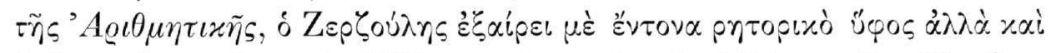

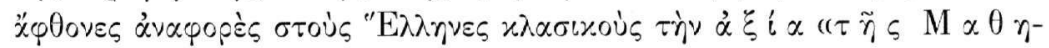

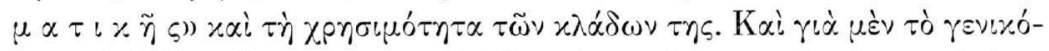

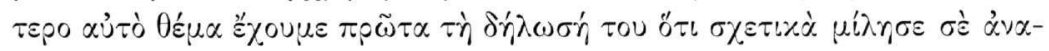

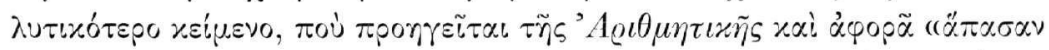

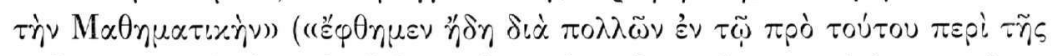

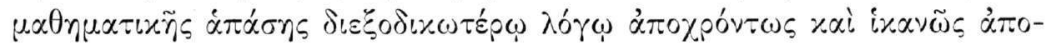

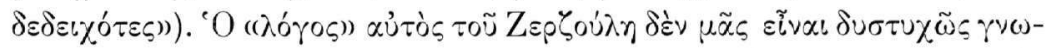

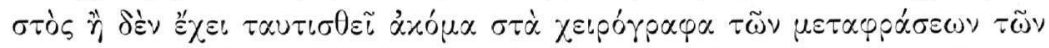

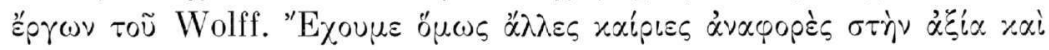

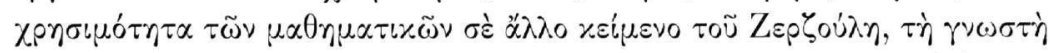

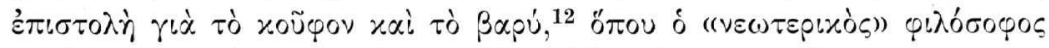

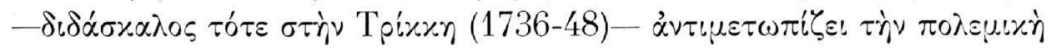

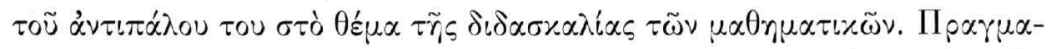

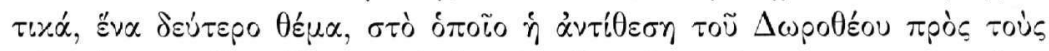

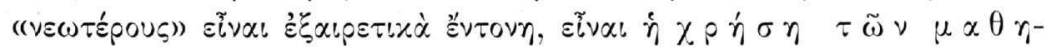

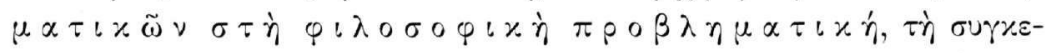

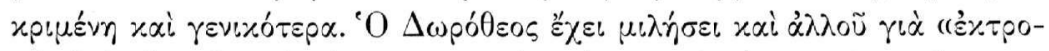

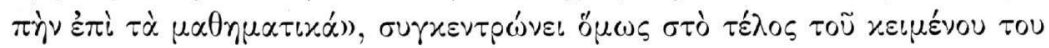

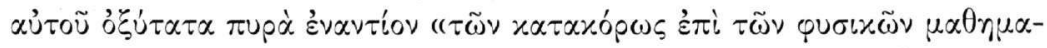

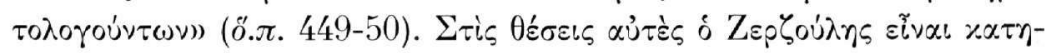

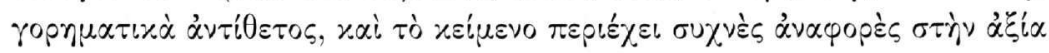

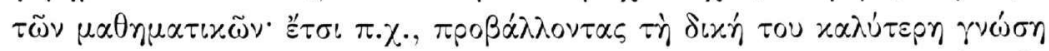

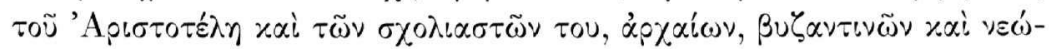

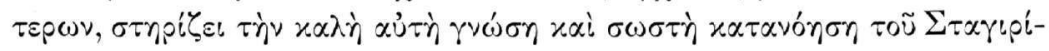

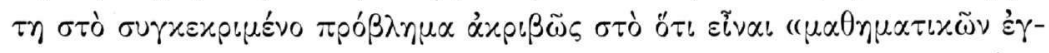

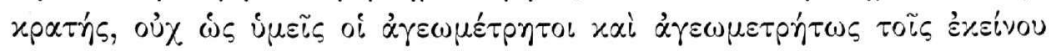

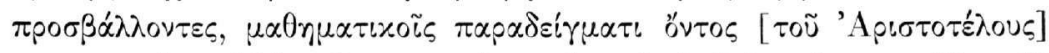

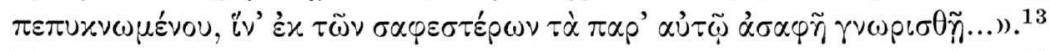

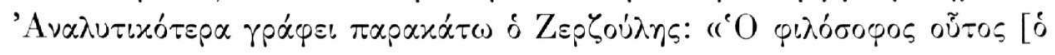

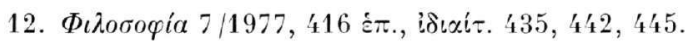

13. "O.л., б. 435-436. 


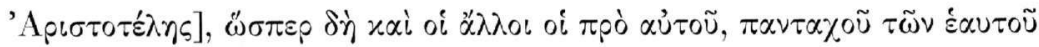

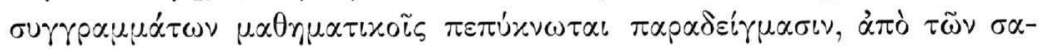

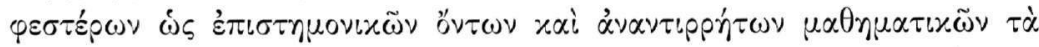

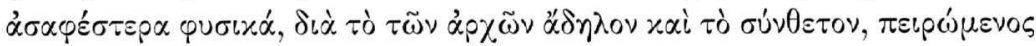

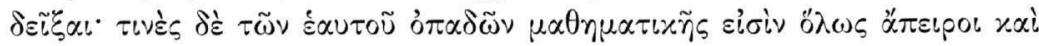

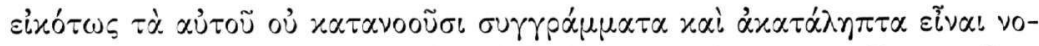

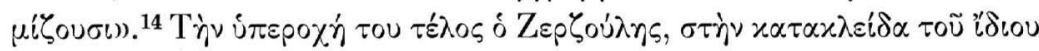

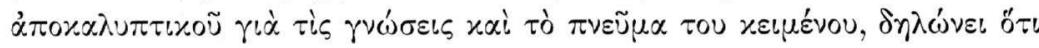

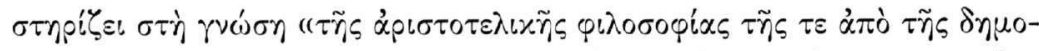

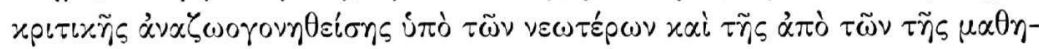

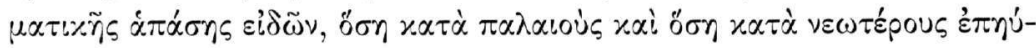

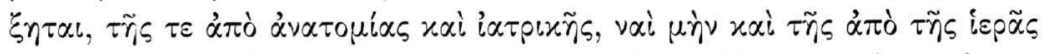

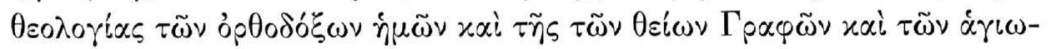

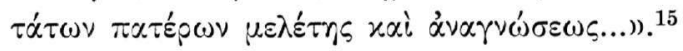

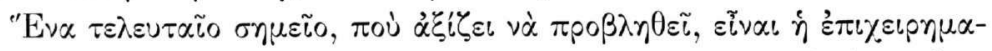

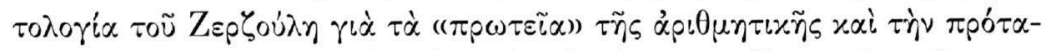

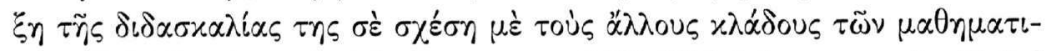

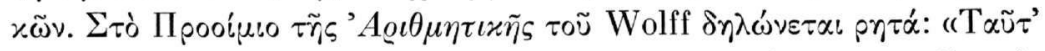

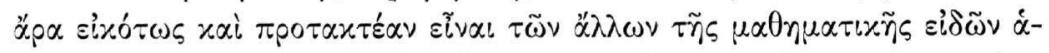

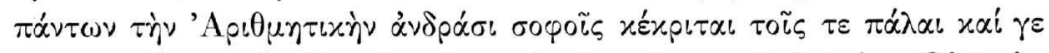

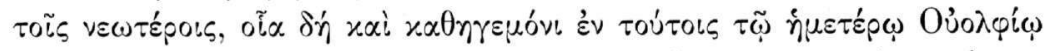

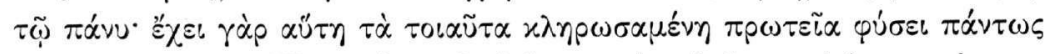

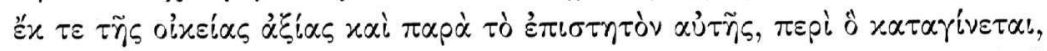

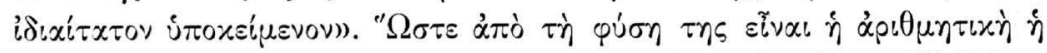

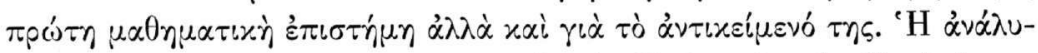

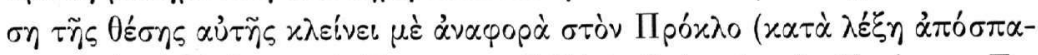

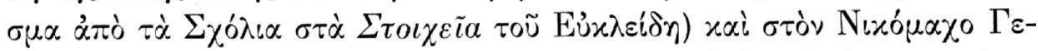

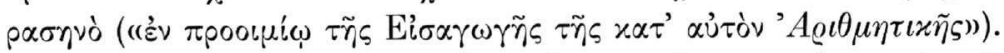

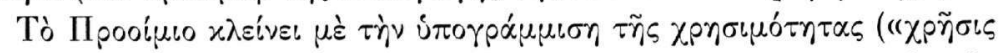

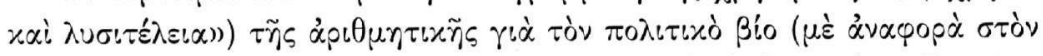

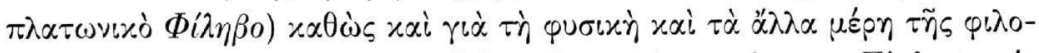

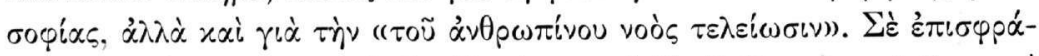

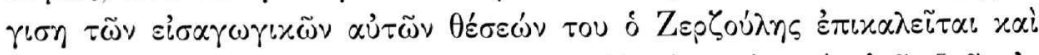

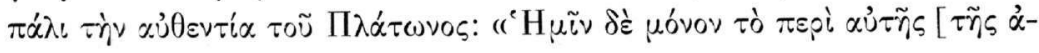

14. "O.л., б. 442.

15. "О.л., б. 445-446. 


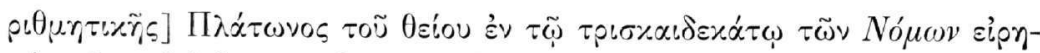

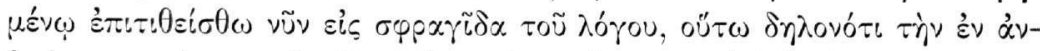

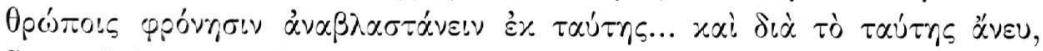

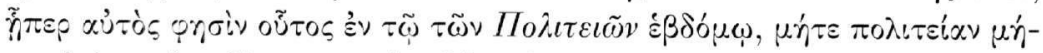

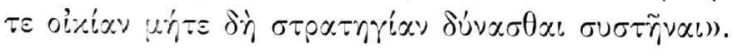

AINOE Г. MIIENAKHL 